\title{
Sustaining biological welfare for our future through consistent science
}

\author{
Yoshihiro Shimomura ${ }^{*}$ and Tetsuo Katsuura
}

\begin{abstract}
Physiological anthropology presently covers a very broad range of human knowledge and engineering technologies. This study reviews scientific inconsistencies within a variety of areas: sitting posture; negative air ions; oxygen inhalation; alpha brain waves induced by music and ultrasound; $1 / f$ fluctuations; the evaluation of feelings using surface electroencephalography; Kansei; universal design; and anti-stress issues. We found that the inconsistencies within these areas indicate the importance of integrative thinking and the need to maintain the perspective on the biological benefit to humanity. Analytical science divides human physiological functions into discrete details, although individuals comprise a unified collection of whole-body functions. Such disparate considerations contribute to the misunderstanding of physiological functions and the misevaluation of positive and negative values for humankind. Research related to human health will, in future, depend on the concept of maintaining physiological functions based on consistent science and on sustaining human health to maintain biological welfare in future generations.
\end{abstract}

Keywords: Biological benefit, Ergonomics, Inconsistency, Integrative thinking, Physiological function, Universal design

\section{Review}

Physiological anthropology encompasses the fields of what is good and comfortable in the design of tools, environments, or systems based on human characteristics, in order to increase the quality of life. The perspective of physiological anthropology, in terms of research methodology, is much broader than that of other research disciplines. For example, a 'human being' has many meanings in human science, such as a pure biological entity [1], an anthropological entity that progressively forms cultures and societies [2], a maker or user of artificial materials or environments [3,4], and a task-based entity, such as that discussed by Rasmussen [5]. However, all aspects of previous research regard humankind scientifically, and researchers believe that analytical methodology is the way to categorize humans in discrete detail, even though an individual comprises a unified set of whole-body functions. Brewer and Hsiang [6] described multidisciplinary human science and engineering, such as ergonomics, as targeting future challenges. They consider that methodological unification and its expansion are important. Boff [7] described

\footnotetext{
* Correspondence: shimomura@faculty.chiba-u.jp

Graduate School of Engineering, Chiba University, Chiba, Japan
}

revolutions and shifting paradigms of ergonomics over four generations, in fields ranging from the workplace and biomechanical capability to the biological enhancement of physical or cognitive capabilities. The emerging ethical problem that they highlight is the relationship between human beings and technology, and they warn us of the importance of optimal integration. On the other hand, the technological adaptability and physiological polymorphism described by Sato [8] and its application to manufacturing and design [9] might provide researchers with a basic concept for considering how human beings, who have evolved over a period of five million years, should adapt to the explosive development of today's technological environment. Although some studies, such as these conceptual frameworks, have attempted to lead future human science, the philosophy of science for the welfare of humanity remains obscure because the word 'human' remains undefined and the concept of the 'human' varies between researchers. Therefore, this present study reviews scientific inconsistencies resulting from analytical considerations of technology and human beings, and discusses these issues from various perspectives to advance interpretations based on integrative thinking. The items discussed in this study refer to 
keywords in scientific design considerations in physiological anthropology [10], and were selected to contain a variety of areas of human science, such as the musculoskeletal, circulatory, and central nervous systems, brain function, and stress relief. A concept for today's human technological lifestyle is proposed from the perspective of sustained biological welfare for future generations.

\section{Is there a consistent understanding of 'human'?}

Although all previous studies of human science and engineering with a proper purpose and valid experimental techniques must be correct in terms of analytical science and a single understanding of what 'human' means, inconsistencies have arisen. These examples help to clarify these scientific inconsistencies and provide a platform for discussion.

\section{Sitting posture for video display terminal workers}

To fit the height of a chair to a human leg and lean the head downward a little is held to be common-sense ergonomics for video display terminal (VDT) workers [11-13] (Figure 1). However, a horizontal seat pan forms a smaller angle between the spinal column and the thigh, and is thus associated with an unequal distribution of tension in the ligaments and muscles of the anterior and posterior sides of the spine $[14,15]$ because of post-bending the spinal column [16-18]. Although some declination of the head might help to avoid eyestrain, the shoulders and neck must stiffen to support the weight of the head (about $5 \mathrm{~kg}$ ) via steady-state activation of the trapezius and neck extensor muscles $[19,20]$. Since the earliest phase of ergonomics, no researcher has been able to design the most appropriate chair. The problem of designing a chair is a typical example of the issues that require integrative thinking about physiological functions of the total body, such as overall spine biomechanics, blood flow, leg edema, digestion, and cognitive function.

\section{Negative air ions}

Many reports have scientifically explained the comfort gained from being near a waterfall or a forest where negative ions are in the air. Some have demonstrated that negative air ions reduce physiological and psychological stress and exert positive effects on human beings [21-23]. In contrast, others contradict these findings $[24,25]$. One study even demonstrated that electrically generated negative ions in air can cause pathological damage [26].

Thinking rationally, molecular clusters of water [27] are not large enough to be absorbed through the pulmonary alveoli. The reduction in stress markers might simply have been caused by humidity generated by water protecting the skin and mucosa, along with possible negative ions in the air [28].

\section{Oxygen inhalation}

'Oxygen bars' have recently become popular as thought is supposedly clarified, and recovery from fatigue is rapid. However, the typical arterial oxygen saturation of a healthy individual is just above 95\% [29]. Moreover, measurements of blood flow in the cerebral cortex demonstrate that astrocytes control the functional hyperemia and result in sufficient oxygen to match the amount of consumption [30].

It is, in fact, not known whether an excess of oxygen exceeds the balance of homeostasis in blood. Superfluous and long-term oxygen inhalation might increase the production of free radicals [31], and might be deleterious to health [32,33]. Researchers must consider not only the
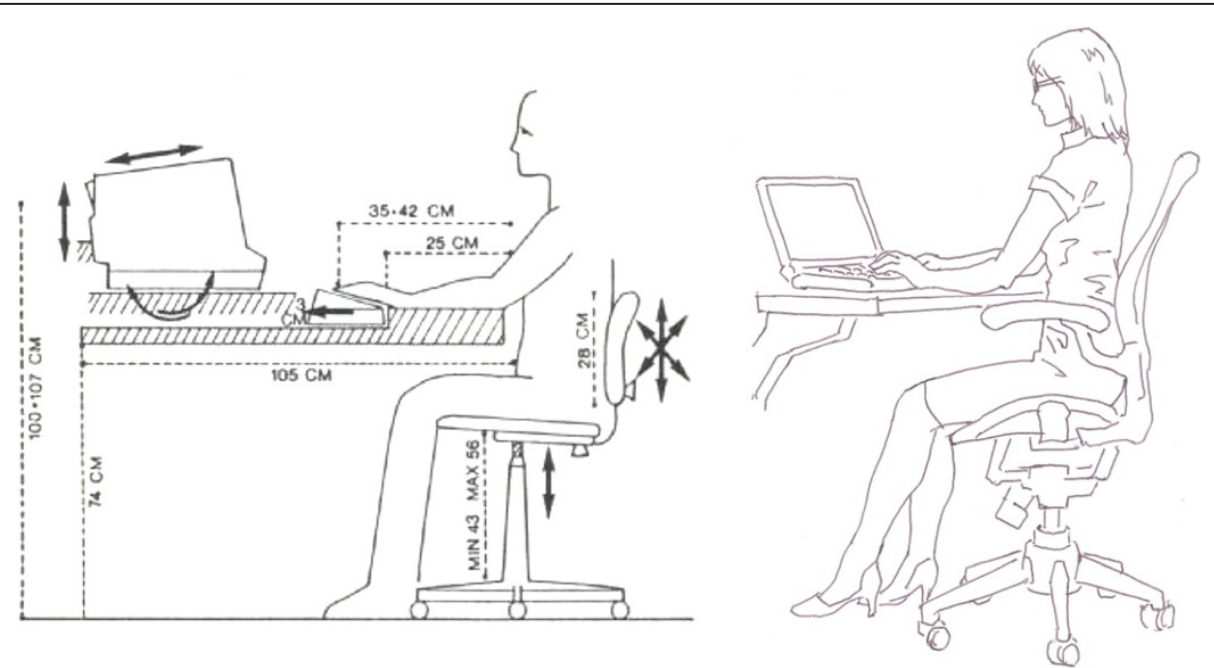

Figure 1 The proper sitting posture commonly recommended by researchers. The picture on the left was drawn by Grieco [71] and that on the right shows that recent trends have not changed at all since then. 
immediate effects of the technology but also the long-term effect of its continuous application.

\section{Alpha waves induced by relaxation music}

Many types of music might increase the quantity of alpha brain waves, as measured in electroencephalograms. Iwaki et al. [34] showed an increase in alpha band amplitude with music stimulation, while Kawasaki et al. [35] clarified that music-induced pleasure increases the intensity of the alpha waves. Many reports have indicated that the production of alpha waves is increased by relaxation.

Incidentally, one study has shown that rates of alpha waves increased more during an experiment with relaxation audio stimuli than with a general music. However, the subject of that experiment had closed his eyes as the relaxation audio was played. This was reflected as changes in brain activity with or without vision-processing [36]. Because human beings are the sum of a total of many body functions, to isolate and consider only a single part of the whole is treacherous. Physiological indexes should be correctly interpreted.

\section{Ultrasound can be perceived}

Ultrasound found in nature, wind chimes, and gamelan music is generally thought to induce relaxation with an increase of the alpha-wave activity [37-39]. However, an auditory brainstem response to ultrasonic tone bursts at a suitable amplitude modulation showed that the sound does not reach the brain stem [40]; that is, humans cannot perceive ultrasonic sound.

Ultrasonic vibration signals delivered as experimental sound stimuli through speakers might lead to slight distortion [41] within the audible range [42], and possibly generate a different sound. The use of more precise technology to evaluate human perception should resolve this inconsistency.

\section{$1 / f$ fluctuations}

The vibration or periodic phenomenon in which amplitude or power is inversely proportional to frequency, especially in logarithmic scales, is defined as $1 / f$ noise [43]. High- and low-frequency vibrations should have a small and a large amplitude, respectively, and the amplitude should be infinite at a direct current content of $0 \mathrm{~Hz}$, if energy equilibrium is assumed. The $1 / f$ property is a very appropriate and convenient means to explain natural periodic phenomena in statistical mechanics.

Biological parameters, such as heart rate and electroencephalograms, follow $1 / f$ fluctuations [44-46]. However, respiratory sinus arrhythmia $[47,48]$ is absent if heart rate variability maintains $1 / f$ scaling. Furthermore, $1 / f$ properties do not show dominant bands, such as alpha waves, in electroencephalograms [49]. Living things, from microbes to human, control statistical probability by coordinating their organs to complete themselves. Therefore, inductive thinking based on statistical equivalence might not be the most appropriate way to explain the whole body of a living thing.

\section{Evaluation of feelings using surface \\ electroencephalography}

Several reports have discussed the determination of feelings and emotions using electroencephalography [50-52]. According to the somatic-marker hypothesis [53], emotion is the result of a series of changes in body states, such as the defense and stress reaction, in which the amygdala processes input signals from whole-body receptors. The hypothalamus, hypophysis, and brain stem in the deeper part of brain control these body states.

Native emotions, such as fear and joy, are adaptive systems automated by the limbic system and the Papez circuit [54,55], whereas the frontal lobe and ventral medial field change physiological states through native emotion circuits to express more complex acquired emotions, such as sympathy, jealousy, or pleasure. The insular cortex and the somatosensory cortex area perceive body reactions in emotions, and then the frontal area processes information and builds feelings based on individual experience and memory. Feelings are induced through such multi-regional coordinated processes. Thus, measuring feelings with only a surface electrode is theoretically impossible. The limitations of a methodology should be strictly understood by researchers, if they are to form a valid description of what is 'human'.

\section{Kansei}

Kansei is the ability to recognize by intuition [8]. This ability is cultivated by bypassing the perception of a somatic reaction [53] by the frontal lobe, such as the orbitofrontal cortex via the insular cortex and other limbic regions $[56,57]$. Somatic reactions are marked by the frontal lobe as positive or negative, and the internal end point can be judged immediately without any intervening stage or conscious use of reasoning [8]. Decision-making by an individual is not always rational and logical, but can be illogical and intuitive. Linguistic explanations and social thinking occur thereafter. Therefore, subjective evaluation that can be described in symbols does not express Kansei. Studies of Kansei engineering [58-60] might not have necessarily evaluated Kansei appropriately.

In addition, the range of the Kansei reach is restricted within individual experience and is very narrow, which is a drawback for designers.

\section{Universal design}

Currently, universal design is the adaptation of a product or environment to various users by involving a group that is challenged by some obstacle or by age [61-63]. 
This is the same as improving usability and accessibility for a classified user group.

Nominally, human beings have a large brain, dexterity, and the ability to walk. However, morphological, functional, and cultural aspects vary considerably among worldwide populations. Essential discussions about what is universal for human beings, the nature of design and what it is to be human do not exist in the current literature. This condition is insufficient for the establishment of a 'universal' science.

\section{Anti-stress}

The reduction of physiological stress is very important in many of today's human sciences, such as ergonomics [64-67]. However, humanity cannot maintain mental and physiological functions without stress. All current industrial products and environmental designs have focused on suppressing stress in human beings to achieve comfort and to remove inconveniences or difficulties from the environment. Technology has now reached a point where disuse atrophy (Figure 2), potential reduction, and functional degeneration are significantly promoted. Stress is simply a reaction to a stressor, so good and bad stress originally had no meaning. Stress should be carefully addressed by integrative thinking, especially in physiological anthropology, rather than based solely on research from individual disciplines.

\section{Expectations for consistent science}

Scientific inconsistencies caution that human beings should not be interpreted from a single intelligible analytical perspective. Intelligible analytical science will deprive humanity of the opportunity for integrative thought [68-70]. Thus, if arguments range across various disciplines, inconsistencies will frequently arise, even if each study is appropriate in

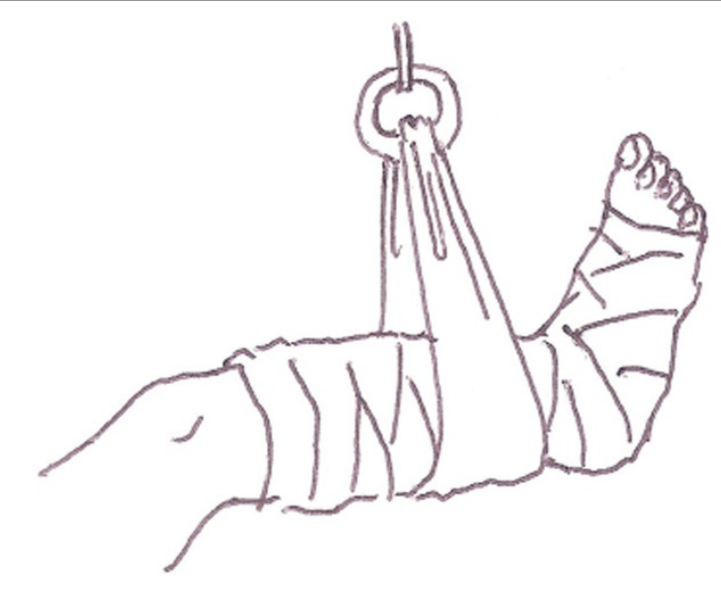

Figure 2 Symbol of a quiet state. terms of analytical details. The perspective of physiological anthropology is much wider than that of other research disciplines, so it essentially has an interdisciplinary methodology. Physiological anthropologists should not be satisfied with only an analytical way of science.

As noted by Sato [8], modern human beings evolved through harsh environmental conditions over a period of about five million years. All human physiological functions were created solely to adapt to nature. Today's human sciences appear simply to detail observations of human beings in terms of only single aspects of evolutionary outcomes and might forget that human beings have a long history of adapting to nature. Therefore, researchers should think not only about the phenomenon currently facing them but also of the physiological functions that comprise the total human being.

To maintain present conditions and quality of life would be impossible without the support of life engineering, antibiotic, and medical technologies. For human science to progress under such circumstances, the concept of maintaining physiological functions and expanding biological adaptation ability by suitable stress management should perhaps be based on consistent science. In addition, the health of Homo sapiens should be sustained to establish a biological welfare that will persist for generations to come.

Human beings have invented various devices and created tools and viable environments over five million years of evolution. This process is an act of design that is unique to humankind and it mostly engages integrative thinking. Physiological anthropology could also be considered as the discipline for developing the human act of design. A significant argument regarding the future of physiological anthropology will hopefully be generated with respect to integrative scientific research and a steadfast vision of the future of humanity based on current technological lifestyles.

\section{Conclusion}

Scientific inconsistencies warn of the importance of integrative thinking and the biological benefit to humanity. We propose that physiological functions based on consistent science should be considered so that health, or biological welfare, can be sustained over the long term.

\section{Abbreviation \\ VDT: video display terminal.}

\section{Competing interests}

The authors declare that they have no competing interests.

\section{Authors' contributions}

YS conceived and wrote the manuscript. TK conceived and helped to draft the manuscript. Both authors have read and approved the final manuscript. 


\section{References}

1. Singleton WT: The Body at Work: Biological Ergonomics. Cambridge: Cambridge University Press; 1982

2. Avison DE, Myers MD: Information systems and anthropology: an anthropological perspective on IT and organizational culture. Inform Tech People 1995, 8(3):43-56.

3. livari J, livari N: Varieties of user-centeredness. In Proceedings of the 39th Annual Hawaii International Conference on System Sciences: 4-7 Jan 2006; Kauai, Hawaii. Edited by Sprague R. Los Alamitos, CA: IEEE Computer Society Press; 2006:176a (8).

4. Meulen PA, Pruett CJ: Digital human models: what is available and which one to choose. In Proceedings of the Human Factors and Ergonomics Society 45th Annual Meeting: 8-12 Oct 2001; Minneapolis/St. Paul, Minnesota. Santa Monica, CA: The Society; 2001:875-879. 5.

5. Rasmussen J: Skills, rules, and knowledge: signals, signs, and symbols, and other distinctions in human performance models. IEEE Trans Syst Man Cybern 1983, 13(3):257-266.

6. Brewer JD, Hsiang SM: The 'ergonomics paradigm': foundations, challenges and future directions. Theor Issues Ergon 2002, 3(3):285-305.

7. Boff KR: Revolutions and shifting paradigms in human factors \& ergonomics. Appl Ergon 2006, 37(4):391-399.

8. Sato M: The development of conceptual framework in physiological anthropology. J Physiol Anthropol Appl Human Sci 2005, 24(4):289-295.

9. Nakamura M, Fuwa T, Inoue K, Iwasaki F, Kudo S, Sako H, Sato M, Shimomura Y: Prospect of manufacturing and design based on physiological polymorphism. J Physiol Anthropol 2007, 26(4):507-511.

10. Takagi Y, Harada H, Maeda T, Sato M: Physiological anthropology design: a comparative study between Germany and Japan.J Physiol Anthropol 2006, 25(1):55-57.

11. Turville KL, Psihogios JP, Ulmer TR, Mirka GA: The effects of video display terminal height on the operator: a comparison of the 15 degree and 40 degree recommendations. Appl Ergon 2006, 29(4):239-246.

12. Saito S, Piccoli B, Smith MJ, Sotoyama M, Sweitzer G, Villanuevai MBG, Yoshitake R: Ergonomic guidelines for using notebook personal computers. Technical Committee on Human-Computer Interaction, International Ergonomics Association. Ind Health 2000, 38(4):421-434.

13. Jamjumrus N, Nanthavanij S: Ergonomic intervention for improving work postures during notebook computer operation. I Hum Ergol (Tokyo) 2008, 37(1):23-33.

14. Mandala AC: The seated man (Homo Sedens) and the seated work position. Theory and practice. Appl Ergon 1981, 12(1):19-26.

15. Keegan JJ: Alterations of the lumbar curve related to posture and seating. J Bone Joint Surg Am 1953, 35-A(3):589-603.

16. Claus AP, Hides JA, Moseley GL, Hodges PW: Is 'ideal' sitting posture real? Measurement of spinal curves in four sitting postures. Man Ther 2009, 14(4):404-408

17. Claus AP, Hides JA, Moseley GL, Hodges PW: Sitting versus standing: does the intradiscal pressure cause disc degeneration or low back pain? J Electromyogr Kinesiol 2008, 18(4):550-558

18. Callaghan JP, Dunk NM: Examination of the flexion relaxation phenomenon in erector spinae muscles during short duration slumped sitting. Clin Biomech 2002, 17(5):353-360.

19. Villanueva MBG, Jonai H, Sotoyama M, Hisanaga N, Takeuchi Y, Saito S: Sitting posture and neck and shoulder muscle activities at different screen height settings of the visual display terminal. Ind Health 1997, 35(3):330-336.

20. Caneiro JP, O'Sullivan P, Burnett A, Barach A, O'Neil D, Tveit O, Olafsdottir K: The influence of different sitting postures on head/neck posture and muscle activity. Man Ther 2010, 15(1):54-60

21. Malik A, Singh K, Singh M: Effect of negative air ions on physiological and perceived psychological stress during computer operation. Int JEnviron Health 2010, 4(1):67-77.

22. Ryushi T, Kita I, Sakurai T, Yasumatsu M, Isokawa M, Aihara Y, Hama K: The effect of exposure to negative air ions on the recovery of physiological responses after moderate endurance exercise. Int J Biometeorol 1998, 41(3):132-136

23. Gail T, Poole MF, Galla J, Berrier J: The influence of negative air ions on human performance and mood. Hum Factors 1981, 23(5):633-636.

24. Hedge A, Collis MD: Do negative air ions affect human mood and performance? Ann Occup Hyg 1987, 31(3):285-290.
25. Albrechtsen O, Clausen V, Christensen FG, Jensen JG, Møller T: The influence of small atmospheric ions on human well-being and mental performance. Int J Biometeorol 1978, 22(4):249-262.

26. Cai K, Liu X, Xu Y, Ren C, Chen H, Xu J, Yu Z: Damage effects induced by electrically generated negative air ions in Caenorhabditis elegans. Sci Total Environ 2008, 401(1-3):176-183.

27. Kobara H, Tamiya M, Wakisaka A, Fukazu T, Matsuura K: Relationship between the size of mist droplets and ethanol condensation efficiency at ultrasonic atomization on ethanol-water mixtures. AICHE J 2010, 56(3):810-814.

28. Kubota A: Distribution characteristics of the negative ion in the vicinity of erosion control (Sabo) facilities, torrents and their riparian forests (in Japanese). Sci B Fac Agr Kyushu 2006, 61(1):33-38.

29. Yoshiya I, Shimada Y, Tanaka K: Spectrophotometric monitoring of arterial oxygen saturation in the fingertip. Med Biol Eng Comput 1980, 18(1):27-32.

30. Gordon GRJ, Mulligan SJ, MacVicar BA: Astrocyte control of blood flow. In Astrocytes in (Patho) Physiology of the Nervous System. Edited by Parpura V, Haydon PG. New York: Springer Science; 2009:461-486.

31. Aruoma Ol: Free radicals, oxidative stress, and antioxidants in human health and disease. J Am Oil Chem Soc 1998, 75(2):199-212.

32. Halliwell B, Gutteridge JMC: Free Radicals in Biology and Medicine. 4th edition. New York: Oxford University Press; 2007.

33. Clark JM, Lambertsen CJ: Pulmonary oxygen toxicity: a review. Pharmacol Rev 1971, 33(2):37-133.

34. Iwaki T, Hayashi M, Hori T: Changes in alpha band EEG activity in the frontal area after stimulation with music of different affective content. Percept Mot Skills 1997, 84(2):515-526.

35. Kawasaki M, Karashima M, Saito M: Effect of emotional changes induced by sounds on human frontal alpha-wave during verbal and non-verbal tasks. Int J Biomed Eng Technol 2009, 2(3):191-202.

36. Chen ACN, Feng W, Zhao H, Yin Y, Wang P: EEG default mode network in the human brain: spectral regional field powers. Neurolmage 2008, 41(2):561-574.

37. Oohashi T, Nishina E, Honda M, Yonekura Y, Fuwamoto Y, Kawai N, Maekawa T, Nakamura S, Fukuyama H, Shibasaki H: Inaudible highfrequency sounds affect brain activity: hypersonic effect. J Neurophysiol 2000, 83(6):3548-3558.

38. Oohashi T, Kawai N, Nishina E, Honda M, Yagi R, Nakamura S, Morimoto M, Maekawa T, Yonekura Y, Shibasaki H: The role of biological system other than auditory air-conduction in the emergence of the hypersonic effect. Brain Res 2006, 1073-1074:339-347.

39. Yagi R, Nishina E, Honda M, Oohashi T: Modulatory effect of inaudible high-frequency sounds on human acoustic perception. Neurosci Lett 2003, 351(3):191-195.

40. Katsuura T, Huang J, Jin X, Liu X, Shimomura Y, Iwanaga K: Physiological measurements for evaluation of human-environment system. J Human Environ Syst 2006, 9(1):1-6.

41. Tan $C T$, Moore BCJ, Zacharov N: The effect of nonlinear distortion on the perceived quality of music and speech signals. J Audio Eng Soc 2003, 51(11):1012-1031.

42. Ashihara K, Kiryu S: Intermodulation distortions of loudspeakers induced by complex tones with components at frequency higher than audible frequency (in Japanese). J Acoust Soc Jap 1999, 55(4):256-264.

43. Hooge FN, Kleinpenning TGM, Vandamme LKJ: Experimental studies on 1/f noise. Rep Prog Phys 1981, 44(5):479-532.

44. Kobayashi M, Musha T: 1/f fluctuation of heartbeat period. IEEE Trans Biomed Eng 1982, 29(6):456-457.

45. Musha T, Yamamoto M: 1/f fluctuations in biological systems. In Proceedings of the 19th Annual International Conference of the IEEE Engineering in Medicine and Biology Society: 30 Oct - 2 Nov. 2 1997; Chicago. Edited by Jaeger RJ, Piscataway NJ. Piscataway, NJ: Institute of Electrical and Electronics Engineers; 1997:2692-2697. 6.

46. Allegrini P, Menicucci D, Bedini R, Fronzoni L, Gemignani A, Grigolini P, West BJ, Paradisi P: Spontaneous brain activity as a source of ideal $1 / f$ noise. Phys Rev E Stat Nonlin Soft Matter Phys 2009, 80(6 Pt 1):061914.1-061914.13.

47. Hirsch JA, Bishop $B$ : Respiratory sinus arrhythmia in humans: how breathing pattern modulates heart rate. Am J Physiol 1981, 241(4):H620-H629.

48. Kobayashi $\mathrm{H}$ : Does paced breathing improve the reproducibility of heart rate variability measurements? J Physiol Anthropol 2009, 28(5):225-230.

49. Pritchard WS: The brain in fractal time: 1/f-like power spectrum scaling of the human electroencephalogram. Int J Neurosci 1992, 66(1-2):119-129. 
50. Ishino K, Hagiwara M: A feeling estimation system using a simple electroencephalograph. In 2003 IEEE International Conference on Systems, Man and Cybernetics: System security and assurance: 5-8 Oct, 2003; Washington, D.C. Piscataway, NJ: Institute of Electrical and Electronics Engineers; 2003:4204-4209.

51. Hu J, Nakanishi M, Matsumoto K, Tagaito H, Inoue K, Shima K, Torii K: A method of usability testing by measuring brain waves. IEEE Trans Software Eng 1999, 25(4):474-491.

52. Musha T, Terasaki Y, Haque HA, Ivamitsky GA: Feature extraction from EEGs associated with emotions. Artif Life Robot 1997, 1(1):15-19.

53. Damasio AR, Everitt BJ, Bishop D: The somatic marker hypothesis and the possible functions of the prefrontal cortex. Philos Trans R Soc Lond B Biol Sci 1996, 351(1346):1413-1420.

54. Papez JW: A proposed mechanism of emotion. J Neuropsychiatry Clin Neurosci 1937, 7(1):103-112.

55. Vertes RP, Albo Z, Prisco GVD: Theta-rhythmically firing neurons in the anterior thalamus: implications for mnemonic functions of Papez's circuit. Neuroscience 2001, 104(3):619-625.

56. Kringelbach ML, Rolls ET: The functional neuroanatomy of the human orbitofrontal cortex: evidence from neuroimaging and neuropsychology. Prog Neurobiol 2004, 72:341-372.

57. Stern ER, Gonzalez R, Welsh RC, Taylor SF: Updating beliefs for a decision: neural correlates of uncertainty and underconfidence. J Neurosci 2010, 30(23):8032-8041.

58. Jindo T, Hirasago K: Application studies to car interior of Kansei engineering. Int J Ind Ergon 1997, 19(2):105-114.

59. Jiao JR, Zhang $Y$, Helander M: A Kansei mining system for affective design. Expert Syst Appl 2006, 30(4):658-673.

60. Nagamachi M: Perspectives and the new trend of Kansei/affective engineering. TQM J 2008, 20(4):290-298.

61. Burgstahler S: Distance learning: universal design, universal access. Educ Technol Rev 2002, 10(1):20-31.

62. Mamee W, Sahachaisaeree N: Public toilet design criteria for users with walking disability in conjunction of universal design paradigm. Procedia Soc Behav Sci 2010, 5:1246-1250.

63. Story M, Mueller J, Mace R: The Universal Design File: Designing for People of All Ages and Abilities. North Carolina State University: Raleigh: Center for Universal Design; 1998.

64. Smith MJ, Sainfort PC: A balance theory of job design for stress reduction. Int J Ind Ergon 1989, 4(1):67-79.

65. Arnetz BB: Techno-stress: a prospective psychophysiological study of the impact of a controlled stress-reduction program in advanced telecommunication systems design work. J Occup Environ Med 1996, 38(1):53-65.

66. Schaubroeck J, Ganster DC, Fox ML: Dispositional affect and work-related stress. J Appl Psychol 1992, 77(3):322-335.

67. Hobfoll SE: Conservation of resources: a new attempt at conceptualizing stress. Am Psychol 1989, 44(3):513-524.

68. Westerhoff HV, Palsson BO: The evolution of molecular biology into systems biology. Nat Biotechnol 2004, 22(10):1249-1252.

69. Sill DJ: Integrative thinking, synthesis, and creativity in interdisciplinary studies. J Gen Educ 1996, 45(2):129-151.

70. Brown T: Design thinking. Harv Bus Rev 2008, 86(6):84-93.

71. Grieco A: Sitting posture: an old problem and a new one. Ergonomics 1986, 29(3):345-362.

\section{Submit your next manuscript to BioMed Central and take full advantage of:}

- Convenient online submission

- Thorough peer review

- No space constraints or color figure charges

- Immediate publication on acceptance

- Inclusion in PubMed, CAS, Scopus and Google Scholar

- Research which is freely available for redistribution

Submit your manuscript at www.biomedcentral.com/submit 